\title{
USAGE OF DIGITAL TOOLS AND SOCIAL MEDIA FOR LEARNING: UKRAINIAN EXPERIENCE IN THE CONTEXT OF THE COVID-19 PANDEMIC
}

\author{
Oleh Sosniuk ${ }^{1}$ \\ Iryna Ostapenko ${ }^{2}$
}

DOI: https://doi.org/10.30525/978-9934-26-076-6-23

In the context of the COVID-19 pandemic, the process of higher education in many countries has been transformed into online format. Thanks to this, even in traditional universities, digital tools and technologies have become more actively used. For a long time, the implementation of the latest learning technologies in the Ukrainian educational environment has been rather slow. Most university lecturers, and especially school teachers, have used modern digital tools to teach sporadically and unsystematically. However, due to the COVID-19 pandemic, the situation in the field of education has changed significantly. Under the pressure of circumstances, the learning process was transformed into an online format. This has forced educators to quickly master new tools, resources and platforms suitable for distance learning. Restructuring of the educational process and its adaptation to new conditions was not an easy task. Not only lecturers and teachers, but also students experienced certain difficulties. As it turned out during the transition period at the beginning of quarantine, most students are quite well versed in a variety of gadgets, useful programs and applications, but mostly for fun and communication. At the same time, a significant number of students were not fully prepared to use their own digital skills in the learning process. Thus, the issues of increasing the digital competence of lecturers, teachers and students came to the fore. However, increasing digital competence could not be the only important direction that provides transformation of the educational process into an online format. Creation and maintenance of proper motivation for learning, development of students' professional and social competence are equally important. All these things can be achieved through the use of Cooperative and Collaborative Learning technologies, which in the context of distance learning require the use of social media and messengers' potential.

In modern science, the terms «digital literacy» and «digital competence» are used simultaneously. As noted by McGarr and McDonagh [4, p. 10] in many cases they are used as synonyms, and the main differences are related to

\footnotetext{
${ }^{1}$ Taras Shevchenko National University of Kyiv, Ukraine

${ }^{2}$ Institute of Social and Political Psychology

National Academy of Educational Sciences of Ukraine, Ukraine
} 
linguistic features. Aesaert et al. define digital competences as the «integrated and functional use of digital knowledge, skills and attitudes» [1, p. 132]. Although the term «digital competence» has not existed for a long time, scientists have proposed a number of interesting models that reveal the structural and substantive features of this notion. A survey by Janssen et al., in which the authors identified twelve different areas that encompass digital competence composing of knowledge, skills, and attitudes [3, p. 473]. The model, that was developed in Digicomp project (an EU funded project aimed at identifying the key components of Digital Competence and developing an overall digital competence framework) is very important for our study. In the first version of this model 5 key areas of digital competence: Information, Communication, Content-creation, Safety, Problem-solving were suggested [2]. A few years later this model was updated. That's how DigiComp 2.0 variant appeared [8]. Based on DigiComp 2.0, a number of interesting Digital Competence concepts have been developed in many European countries. Most of them were analyzed in detail in the work of McGarr and Mcdonagh [4].

Also while choosing digital tools we payed attention to the results of our own research, in which prevalent types of users for the most popular social networks (Facebook, Instagram,Twitter) and messengers (Telegram, Viber) were identified. It is determined that the leading types of users are: for the Facebook - discussion initiator, active discussion participant, conformist; for the Instagram - generator of creolized content, spreader of the creolized content and a follower; for the Twitter - generator of creolized content, spreader of the creolized content and a discussion initiator; for Telegram discussion initiator, active discussion participant, spreader of the creolized content; for Viber messenger - initiator of discussions, active participant of discussions, conformist [6, pp. 160-181]. In the process of transformation of the educational practice, we used methods of active learning, such as: webquest, comics, project-oriented tasks, methods of creating inspiring motivation [5, pp. 72-77; 7, pp. 82-89]. Combined with the use of resources useful for the organization of distance learning (Zoom, Google Meet) and the possibilities of popular in Ukraine social networks (Facebook, Instagram, Twitter), messengers (Telegram, Viber, WhatsApp) - it allowed to solve the problem of digital, professional and social competencies.

We also interviewed lecturers and teachers of various faculties of Taras Shevchenko National University of Kyiv to assess the resources useful for organization of distance learning (Zoom, Google Meet, Google Forms, Kahoot it!) We used the in-depth interview method with lecturers and teachers. After analysing the results of colleagues' survey and their own experience we can determine advantages and limitations of use of the most popular tools among Ukrainian lecturers (Zoom, Google Meet). Both 
platforms provide approximately the same functionality for online learning. However, there are some differences. Zoom provides free connection for members no matter where they have an account, while Google Meet requires members to have a Google account. Zoom also allows you to make digital records for free, while Google Meet provides such functions only in paid versions. However, Google Meet has its advantages. First of all, this is the duration of classes in the free versions $-60 \mathrm{~min}$, while Zoom provides only 40 min. In addition, Google Meet provides better privacy (through data encryption).

Possibilities of using services for knowledge and competencies assessment of students such as Google Forms and Kahoot it! deserved autonomous treatment. According to our colleagues, each of them has its advantages and disadvantages. Kahoot it! Main advantages: in the form of tests you can check the level of students knowledge, you can set time limits for each question (from 20 to 240 seconds); you can set the time until which testing will be open; you can upload a picture or a graphic to a text question. Main disadvantages: a free account allows you to use only two types of tasks: tests (Quiz) and approval / refutation of a thesis (True / False); in tests (Quiz) there are only 4 answer options, but you can choose a few correct answers. Google Forms. Main advantages: uses many more question options: open-ended question, tests (one from the list, several from the list, scale, etc.); integrates with Google Classroom; the results come with analytics; open questions can be checked automatically by keywords. Main disadvantages: there is no time limit for a certain task (in order for the form to be limited in time - you need to install an add - form Limiter -PROD; if the student has not sent a response by the specified time and the form is closed - the answers are not saved.

In the process of transforming learning into an online format, it is important to use active learning methods, such as: web-quest, comics, projectoriented tasks, methods of creating inspiring motivation, etc. In combination with the use of resources useful for the organization of distance learning (Zoom, Google Meet) and the possibilities of popular in Ukraine social networks (Facebook, Instagram, Twitter), messengers (Telegram, Viber, WhatsApp) - it allows solving problems of development of digital, professional and social competences. For operative communication with Ukrainian students the most useful is Telegram, and with foreign students Viber and WhatsApp messengers. It was also found that it is better to discuss the results of certain tasks in closed groups on Facebook, presentations of creative developments - on Instagram, searching tasks - on Twitter. Google Forms and Kahoot it! can be equally useful for assessing students' knowledge and competencies. Each of them has certain shortcomings, so they should be used as complementary. Zoom, Google Meet platforms provide approximately 
the same functionality for organizing online learning. However, the education sector is sensitive to free access. Conditions for free use of Zoom, Google Meet are constantly changing, which leads to the dependence of educators on the marketing policy of these services. That is why the specialists of Taras Shevchenko National University of Kyiv have developed their own educational platform for online learning. Taking into account the disappointing predictions of the COVID-19 pandemic, the online format of education may become the main one for a long time. We are currently testing our platform and hope to report on its features in the future.

\section{References:}

1. Aesaert K., Vanderlinde R., Tondeur J,. van Braak J. (2013) The Content of Educational Technology Curricula: A Cross-Curricular State of the Art. Educational Technology Research and Development, no. 61(1), pp. 131-151.

2. Ferrari, A. (2012) DIGCOMP: A Framework for Developing and Understanding Digital Competence in Europe. Luxembourg: Publications Office of the European Union.

3. Janssen J., Stoyanov S., Ferrari A., Punie Y., Pannekeet K., Sloep P. (2013) Experts' views on digital competence: Commonalities and differences. Computers \& Education, no. 68, pp. 473-481. DOI: https://doi.org/10.1016/j.compedu.2013.06.008

4. McGarr O., McDonagh A. (2019) Digital Competence in Teacher Education, Output 1 of the Erasmus+ funded Developing Student Teachers' Digital Competence (DICTE) project. Available at: https://dicte.oslomet.no// (accessed 24 May 2020).

5. Sosniuk O., Ostapenko I. (2016) Gamification as an element of active learning in higher education. DisCo 2016: Towards Open Education and Information Society. Papers of 11-th International Conference, Prague, Center of Higher Education Studies, $72-77$.

6. Sosniuk O. P., Ostapenko I. V. (2019) Psychological features of social media users` activity. Ukrainian Psychological Journal, 2(12), 160-181. DOI: https://doi.org/ 10.17721/upj.2019.2(12).12

7. Sosniuk O., Ostapenko I. (2018) The development of media literacy and media competence of students in educational practice. DisCo 2018: Overcoming the Challenges and Barriers in Open Education. Prague, Center of Higher Education Studies, 82-89.

8. Vuorikari R., Punie Y., Gomez S. C., Van Den Brande, G. (2016) DigComp 2.0: The digital competence framework for citizens. Update phase 1: The conceptual reference model (No. JRC101254). Joint Research Centre (Seville). 